\title{
The costs of fragmentation in psychiatry - a national joint conference of the Royal College of Psychiatrists and the College of Occupational Therapists*
}

\author{
Geoffrey Wallis, Consultant Psychiatrist, Fulford Grange Hospital, Micklefield Lane, \\ Rawdon, Leeds LS19 6BA \\ "Absence of occupation is not rest \\ A mind quite vacant is a mind distressed" \\ William Cowper (1731-1800)
}

\begin{abstract}
As a sequel to a scientific meeting between these two Colleges during The Royal College of Psychiatrists' Autumn Quarterly Meeting in October 1987, the Colleges set up a small Liaison Committee, chaired by Professor Ben Sacks. One of its tasks was to organise this joint conference where there assembled 100 occupational therapists, 28 psychiatrists, 27 whose main discipline was in some sense administrative, seven doctors who were concerned principally with public health medicine and eight from the realms of politics, law and social work.

With Lord Ennals taking the chair in the morning and our President in the afternoon, the speakers were Professor Sacks; Graham Lister of Coopers \& Lybrand Deloitte; Margaret Ellis, Chairman of the European Committee of Occupational Therapists; Stephen Dorrell, Parliamentary Under-Secretary for Health; Diana Brahams, a barrister and legal correspondent of The Lancet; Judith Reid, Head Occupational Therapist at the Maudsley Hospital; Professor Julian Leff of the Medical Research Council's Social Psychiatry Research Unit at the Institute of Psychiatry; Mr Louis Blom-Cooper, Vice-President of the College of Occupational Therapists and Chairman of the Mental Health Act Commission; and members of the audience, who made knowledgeable and stimulating contributions to the discussions.
\end{abstract}

\section{Recurring themes}

These were: team work, coordination, as demonstrated by the researches of Mary Test, being vital;

* Held on 12 November 1990 at the Royal Institute of British Architects. skill mix, inevitable because only $40 \%$ of nursing and $50 \%$ of occupational therapy staff working in mental health services were qualified but excellent if purposefully planned; deployment of occupational therapists' time in the community, the preferred targets for the particular expertise and approach of occupational therapists being the acquisition of practical and coping achievements; the welfare of the psychiatric patient in the community, for which there had been more research, most of it favourable to community care, than many of us realised, the closures of Friern and Claybury hospitals having been subjected to stricter evaluation than any other such closure in the world; the consumer voice, fast growing louder and much commended, patients having the potentiality to form a power base and become important allies; funding, for which the majority view seemed to be that increases adumbrated by the Minister were too small to make much difference; business methods, based on the purchaser/provider contract, as opposed to operational, budget allocation methods in psychiatry, the main question being whether psychiatry fitted in well with a businesslike approach; variability in services, which, Mr Blom-Cooper regretted, was "Quixotic and bizarre".

Consensus: several speakers, led by Sheelagh Richards, Chairman of the Council of Occupational Therapists, looked forward to the imminent publication of a statement, compiled by the Liaison Committee, on Occupational Therapy and Mental Disorder and expressed optimism that the fruitful and harmonious teamwork between the two Colleges could extend beyond psychiatry and occupational therapy. 